\title{
Kevin LaGrandeur, James J. Hughes (eds) (2017) Surviving the Machine Age. Intelligent Technology and the Transformation of Human Work. Cham: Palgrave Macmillan. 166 pages. ISBN: 978-3-319-84584-5
}

\section{Claudio Gutierrez}

cgutierr@dcc.uchile.cl

This is a book for those who think about the future, a book that challenges many common sense perceptions about the current organization of society. It addresses the future of work, that ubiquitous activity that many people believe defines us as human.

From the current reality, the authors look for and explore the future social scenarios that work automation is producing. The volume includes contributions from authors with extensive experience and reflection on the subject, coming mainly from the world of entrepreneurship, law, communication, economics, sociology and public policies.

Work is among the human activities most impacted by emerging technologies, particularly in the areas of digital technologies and automation (robotics, artificial intelligence, machine learning, 3D, etc.). This is because work in today's societies is not just a way of making a living, but an activity that gives dignity, self-esteem, socialization and meaning to people's lives. Therefore, it is not surprising that the automation of many jobs and the increasing achievements of the machines appear as a threat to human nature and society. As Thomas D. Philbeck writes in Chapter 6 (p.84), "this technological transformation is challenging socioeconomic stability as it threatens our productive roles as individuals." This is not a new historical phenomenon, as James Clark argues in Chapter 3. Similar trends of 'creative destruction' have already been observed in previous historical periods; but today the acceleration of time, the extent of the disruption produced, geographical globalization and the extension of life expectancy make this transformation unique. Presenting the challenges posed by this transformation is the objective of this book.

For the purpose of this review, I will organize the contents of the book into three main themes and show how each of the ten chapters contributes to them.

The first theme is the scope and characteristics of the current transformation of work and unemployment. In Chapter 1, the editors, based on figures and data from various sources, present the scope of the problems that new technologies pose to traditional work. In Chapter 2, Melanie Swan complements this analysis by presenting the characteristics of current technological unemployment and highlighting its relationship with income inequality. In Chapter 3, James P. Clark addresses methodological issues, such as 'the suffering and the theory, reminding us that the people who lose their jobs in these transformations are not the same as those who get the new ones. This demands political responsibility. He then analyzes the fundamental differences of past and current technological revolutions, claiming that we are experiencing a 'phase change' of human civilization. In Chapter 5, John Danaher draws attention to the close links between technological unemployment and the extension of life. Technology is doing both, helping to extend life and eliminating something that people today consider part of life, that is, work. This opens a rich discussion about ways for future policies in 
this field. Finally, in Chapter 9, James J. Hughes presents a detailed study by type of activities, jobs and professions, both those threatened by new technologies and those that will potentially arise or be created in this new era.

The second theme is what to do in this new scenario. The facts and data presented require actions in the form of new frameworks, models, strategies and policies. In Chapter 6, Thomas D. Philbeck (p.85) considers several "popularly advocated policies and tactics for building resilience into the labor market" and wonders if "these policies will be enough to address the issues of inequality, instability, uncertainty, and growth." In Chapter 8, Yvonne A. Stevens and Gary Marchant (p. 123) discuss several other possible policies and strongly advocate what they call a 'longterm solution': the badge proposal, a reward system for "supplemental goods and services [as opposed to basic income] that are desired but not necessary for basic living." And so we come to new models, new worldviews to address this radically new environment. In Chapter 2, Melanie Swan defends an 'Abundance Economics,' a 'new philosophy of economic theory' arguing that traditional economic notions of material scarcity are no longer valid in today's digital economy. In Chapter 7, Scott Santens discusses 'Unconditional Basic Income' not only as a solution to technological unemployment, but as an opportunity to take a "collective step that is humanity's next giant leap. (p. 115)" In fact, he sees it as "the abolition of enslavement once and for all. (p. 115)" Finally, in Chapter 10, David J. Gunkel analyzes the changes that these transformations are making in the field of training and education. He calls for "reworking educational programs from both ends of the spectrum --developing top-down updates in the structure and operation of the institution and encouraging bottom-up mods that can have immediate impact on the lives and careers of both teachers and students. (p.160)"

The third theme, one that permeates all the chapters, and makes the book so fresh and enjoyable, is reflection and speculation about the future. An iconic chapter in this regard is that of Robin Hanson on "Employment in the Age of Em." An em is a simulation of a particular human brain through a computer system. These 'copies' of people may carry out human labor and work. The thought experiment vividly shows the challenges that not too distant technology will present to humans: the notion of status and property, the scope of functions, the marginalization of groups of humans, competition against humans, etc. As Hansen (p. 61) concludes, "humans are no longer at the center of the world's story during the em era." In such a scenario, the meaning of human life comes out as a central theme.

It is impressive how a nonfiction book can be so fascinating to open the imagination and devise future scenarios. And it is remarkable how in a few pages the authors can explain the reasons for this phenomenon and provoke a reflection on it. As with any book, one could complement and suggest missing issues. Here are some comments from me about it. First, the book is rather biased towards the experience of the United States and Europe. I believe that today the experience of China cannot be ignored (there is a mention of the social credit experiment in Chapter 8), but more importantly: today it is unthinkable to reflect on humanity if the vast majority of the marginalized population (even more deeply by these transformations) in the "south" is not included (Clark touches it in Chapter 3 regarding population). Second, I had the feeling that workers appear in most texts as "others." You keep asking yourself when you read: do the machines work by themselves? Are "we", the human race, involved in this problem as a whole, or is it just a problem of "the workers", those aliens who live on their wages? What would happen if the machines belonged to humanity as common goods? What would be the meaning of "work" in that environment? In some articles you can find sparks from this necessary discussion. But the current socio-economic system as a whole, except for a couple of authors, is not in doubt: sometimes one feels that capitalism and private ownership of machines is the only stable thing, almost like nature, under which we have to discuss the new society that will emerge from these transformations. Third, although it is beyond the scope of the book, one misses a deeper philosophical and humanistic discussion about the very notion of work itself. Today such consideration is not a luxury or a disciplinary issue, but something fundamental to understand what work has meant, 
means and will mean for humanity. In particular, for the topics of this book, it is essential to understand whether or not the work goes beyond an economic need. However, beyond these considerations, the text we are reviewing has the great intellectual value of inspiring these and many other questions.
Therefore, I strongly recommend the book to readers seeking reflections and ideas about our common future, to people who understood that our civilization is experiencing, as Clark says, a phase change. 